\title{
Adult outcome of congenital lower respiratory tract malformations
}

\author{
M S Zach, E Eber
}

Arch Dis Child 2002;87:500-505

C ongenital malformations of the lower respiratory tract are usually diagnosed and managed in the newborn period, in infancy, or in childhood. To what extent should the adult pulmonologist be experienced in this predominantly paediatric field?

There are three ways in which an adult physician may be confronted with this spectrum of disorders. The most frequent type of encounter will be a former paediatric patient, now reaching adulthood, with the history of a surgically treated respiratory malformation; in some of these patients the early loss of lung tissue raises questions of residual damage and compensatory growth. Secondly, there is an increasing number of children in whom paediatric pulmonologists treat respiratory malformations expectantly; these patients eventually become adults with their malformation still in place. Thirdly, there is a small group of patients in whom the malformation goes unrecognised throughout childhood; in these a late complication or the coincidental discovery of a radiographic anomaly may demand a late diagnosis and management in adulthood.

All three of these adult presentations will require some expertise on the part of the managing physician. The subsequent text reviews the most common "classical" congenital malformations of the lower respiratory tract from the above three perspectives.

\section{TRACHEO-OESOPHAGEAL FISTULA (TOF) \\ Paediatric presentation}

TOF usually occurs in association with oesophageal atresia; thus, the outcome is invariably fatal unless the anomaly is surgically repaired in the first days of life. The rare "H type" TOF without oesophageal atresia is an exception to this rule and may persist into later childhood or even adulthood before the diagnosis is established. ${ }^{1}$ The malformation is explained by the defective progression of a complex system of folds that separate the foregut into trachea and oesophagus. ${ }^{2}$ Approximately $50 \%$ of infants with TOF have associated anomalies, most often involving the urinary, gastrointestinal, and cardiac systems. $^{34}$

The first successful repair of oesophageal atresia with TOF was reported in 19435; since then the surgical and perioperative management has improved progressively, achieving a $100 \%$ survival in infants without severe associated anomalies. $^{3}$

\section{Long term outcome}

To understand any long term respiratory morbidity after the successful repair of TOF and oesophageal atresia, one must realise that the tracheal structure is more or less abnormal in most patients, showing disruption of cartilage rings and a concomitant increase in the membranous portion. ${ }^{6}$ This results in tracheomalacia of varying severity which persists far beyond the surgical closure of the TOF and occurs in the majority of patients. ${ }^{7}$ In addition, oesophageal function tends to remain disturbed after the repair of oesophageal atresia; relevant studies have shown absence of the normal peristaltic wave, atonia, and pooling of oesophageal contents. ${ }^{89}$

The clinical course in the first years after repair of TOF is often characterised by a high incidence of chronic respiratory symptoms. ${ }^{90}$ The most typical of these is a brassy, seal-like cough that stems from the residual tracheomalacia. While this "TOF cough" is both impressive and harmless per se, recurrent bronchitis and pneumonitis are also frequently observed. ${ }^{7}{ }^{11}$ In rare cases, however, tracheomalacia can be severe enough to cause life threatening apnoeic spells. ${ }^{72}$ These respiratory symptoms tend to decrease in both frequency and severity with age, and most patients have few or no respiratory complaints by the time they reach adulthood. ${ }^{1314}$

The entire spectrum of residual respiratory morbidity after repair of TOF is not sufficiently explained by tracheomalacia alone. In many patients the remaining abnormalities of oesophageal motility cause dysphagia, oesophagitis, and gastro-oesophageal reflux, and these problems tend to persist well into adulthood. ${ }^{31314}$ There seems to be a correlation between the frequency of bronchitis and pneumonia, on the one hand, and the severity of dysphagia on the other. ${ }^{13}$ Furthermore, lung function testing in TOF survivors tends to reveal a mildly restrictive respiratory impairment indicating additional pathology in the lower respiratory tract. ${ }^{13}{ }^{14}$ All this suggests that some patients tend to aspirate recurrently after the repair of TOF, and this extends the scope of respiratory pathology beyond the malformed trachea. ${ }^{1015}$ Residual oesophageal dysfunction offers itself as the most likely cause for such recurrent aspiration. Scoliosis, which occasionally occurs in patients who have had a TOF repair, is a non-specific long term consequence of thoracotomy. ${ }^{16}$

\section{Late presentation}

TOF without oesophageal atresia is compatible with life and may go unnoticed for years or even decades. Patients may suffer from bouts of coughing after drinking, haemoptysis, retrosternal pain and recurrent pneumonitis.

\section{CYSTIC MALFORMATIONS}

\section{Paediatric presentation}

A spectrum of different, more or less clearly defined, congenital malformations can be listed under this heading. They all have cysts that often (but not necessarily) form a prominent part of the lesion. Surgical resection of the malformation is the most frequently used therapeutic option.

\section{Lung cysts}

Also termed "congenital parenchymal cysts", these lesions are a localised malformation of the terminal bronchopulmonary airway. Depending on their origin, their wall may contain bronchial elements such as cartilage, glands, and smooth muscle, or they may be of a more bullous alveolar type. ${ }^{17}$

Reproduced in full with permission from Thorax 2001;56:65-72 
Lung cysts may occur as a single or a multicystic lesion, can contain fluid, air, or both, and may or may not communicate with the bronchial tree. ${ }^{18}$ The most frequently occurring complication is infection that may enter via rudimentary communications from the airways or via collateral channels, and may lead to protracted pneumonitis and abscess formation. In addition, enlarging cysts may cause compression of the surrounding tissue resulting in atelectasis and/or recurrent pneumonia. Rupture of a cyst may lead to pneumothorax. ${ }^{19}$

Large lesions may cause symptoms postnatally or in infancy but others may remain asymptomatic for years or decades and are only diagnosed by chance or when causing late complications. Diagnostic examination relies on CT scanning; aortography can be used to rule out an aberrant systemic arterial supply to the lesion, thus distinguishing lung cysts from cystic variants of the sequestration spectrum. Surgical resection is usually recommended, especially if the cysts have already caused some complications. ${ }^{19}$ Some paediatric pulmonologists will advocate non-surgical management for smaller asymptomatic lesions diagnosed by chance.

\section{Cystic adenomatoid malformation (CAM)}

CAM is a rare malformation of the non-cartilage-containing terminal respiratory structures. ${ }^{19}$ It consists of cysts and solid airless tissue that, on histological examination, shows predominantly bronchiolar elements. ${ }^{20}$ In the macrocystic type one or more large cysts predominate, the more frequently occurring microcystic type consists mostly of small cysts, while the solid type is a CAM in which a solid airless tissue mass prevails. The lesion may affect part or the whole of one lobe, sometimes two lobes, or even an entire lung. ${ }^{21}$

Many CAMs present with severe respiratory symptoms at birth; large lesions may cause a mediastinal shift and compression of the opposite lung. Occasionally it may be difficult to distinguish CAM from congenital diaphragmatic hernia in an infant with severe respiratory distress. ${ }^{22}$ However, the diagnosis of some lesions may be delayed until infancy, school age, or even adolescence. ${ }^{23}$ These cases present with unresolving pulmonary infiltration, failure to thrive, or pneumothorax. Surgical resection is considered to be the treatment of choice in all cases of CAM. ${ }^{23-25}$ The extent of pulmonary resection will depend on the size of the lesion; some authors advocate surgical techniques that aim to preserve the functional pulmonary tissue that surrounds the malformation. ${ }^{26}$

\section{Pulmonary sequestration}

Pulmonary sequestration is a disconnected or abnormally communicating bronchopulmonary mass or cyst with a normal or anomalous arterial supply and/or venous drainage. ${ }^{19}$ It may occur in two forms. ${ }^{27-29}$ In the more frequent intrapulmonary form the lesion lies within the boundary formed by the pleural layer surrounding the lung, while the rare extrapulmonary form consists of ectopic lung tissue lying outside the boundary formed by the pleural layer that surrounds the rest of the lung.

Roughly two thirds of all pulmonary sequestrations are found in the posterior basal segment of the left lower lobe; the extent of the lesion is usually segmental or less. ${ }^{19} \mathrm{~A}$ bronchial communication is either absent or abnormal, and the lesion may be cystic or not. The aberrant systemic arterial supply arises from the lower thoracic or the upper abdominal aorta or one of its major branches as a single trunk. The venous drainage of a pulmonary sequestration is usually normal to the left atrium but may also be anomalous to the right atrium, vena cava, or azygos system. ${ }^{28} 30$

Clinically, pulmonary sequestration is latent until infection leads to symptoms. Recurrent pneumonitis of the sequestrated segment, fever, but also purulent sputum and haemoptysis then become the prevailing symptoms. ${ }^{29} 31$ Pulmonary sequestration can present clinically at all ages, but most lesions tend to develop these infective complications at school age and adolescence; however, symptoms may also occur in infants and preschool children, as well as in previously asymptomatic adults. ${ }^{27} 2932$ In addition, it may be discovered coincidentally on a chest radiograph taken for another reason. ${ }^{19}$

All symptomatic cases of pulmonary sequestration require surgery which is usually curative. ${ }^{24} 25$ To avoid vascular complications, accurate preoperative assessment by ultrasonography, CT scanning with contrast, and/or conventional angiography are essential. Some authors have advocated embolisation of the aberrant systemic artery at the time of catheterisation which, in a few cases, may result in complete resolution of symptoms and chest radiographic changes. ${ }^{19}$ It thus allows the option of expectant management for a while and, if surgical resection is subsequently considered necessary, the risk of vascular complications is reduced. ${ }^{33}{ }^{34}$

\section{Congenital lobar emphysema (CLE)}

CLE is a massive postnatal overinflation of one or more lobes of the lung. ${ }^{1935} 36$ Approximately half the cases of CLE involve the left upper lobe and the lesion is less frequently located in the right upper or middle lobe. ${ }^{36}$ Congenital heart disease is a common accompaniment of CLE. ${ }^{35}{ }^{37}$ The development of CLE is still poorly understood. Strictly speaking, the term "emphysema" should be based on clearly defined morphological characteristics that are not present in CLE. This has motivated some authors to suggest the alternative term "congenital lobar overinflation"25 but this more accurate nomenclature has never been generally accepted. Some forms of CLE seem to be caused by a bronchial valve mechanism; localised deficiency of bronchial cartilages, bronchial mucosal folds, and also extrinsic compression of the bronchus have been described. ${ }^{19}$ Another form of CLE might be the result of a true alveolar malformation, as some resected lobes have shown a striking increase in the number of their alveoli. ${ }^{38}$

Overdistension of the affected lobe may cause compression of the surrounding lung tissue and displacement of the mediastinum. In severe cases this may manifest as respiratory distress of the newborn. However, later less dramatic manifestations and a coincidental detection of the malformation can occur at any age..$^{39}$ In the past, surgical removal of the affected lobe was the standard recommended treatment. ${ }^{24}{ }^{25}$ However, other reports advocate expectant management and cases of CLE in whom the symptoms gradually resolved have been reported. ${ }^{39}{ }^{40}$ As a result, most paediatric pulmonologists now try conservative supportive treatment before resorting to surgery. Surgical intervention can thus be reserved for those who do not improve with such a trial and those who present as newborn infants with most severe respiratory embarrassment.

\section{Bronchogenic cysts}

Bronchogenic cysts are usually located in the carinal region and may cause symptoms by bronchial compression or when becoming infected. Surgical resection of a bronchogenic cyst is usually performed without sacrifice of pulmonary tissue. ${ }^{24} 25$

\section{Long ferm outcome}

\section{Early resection of lung tissue}

Many cystic malformations are treated by resection of lung tissue performed in infancy or early childhood. The extent of such lung tissue resection depends on the size and complexity of the lesion as well as on surgical expertise and skill. In most cases this intervention will have the dimension of a lobectomy, but occasionally even a pneumonectomy has to be performed early in life. With such a resection of lung tissue the question arises whether and to what extent postoperative compensatory lung growth changes the structure and function of the remaining lung in these children. The respiratory status of an 
adult who has undergone resection of lung tissue early in life will, at least in part, express the end result of such compensatory growth. There is also the related and clinically important question whether compensatory lung growth is more extensive in younger patients, as might be expected if the normal growth and development of the respiratory tract did support and enhance compensatory mechanisms. If this was the case, lung tissue resection should be performed as early in life as possible to ensure maximum structural and functional compensation. Thus, the paediatric pulmonologist, when confronted with a newly diagnosed lung malformation, faces a similar question to the adult pulmonologist who is trying to understand the structure and function of an adult's lower respiratory tract in relation to the timing and extent of a lung tissue resection which the patient has experienced in infancy or childhood.

While these questions are simple and straightforward, definite answers are still lacking. Clearly, the remaining lung increases in size after lobectomy at all ages, and relevant animal studies suggest that it gains in terms of both volume and weight. ${ }^{41}$ However, the lung is a highly expansile organ and it receives the entire cardiac output. Consequently, a marked restoration of both volume and weight could occur without significant addition of tissue or remodelling of structure. Early animal work, however, has indicated that the increase in weight after pneumonectomy is caused by an actual increase in tissue. ${ }^{42}$ This again raises the question whether such an increase in tissue leads to the formation of new alveoli (alveolar multiplication) or to enlargement of the existing structures. In spite of the application of modern morphometric techniques, relevant studies do not offer a clear answer to this question. ${ }^{41}{ }^{43}$ Furthermore, it has been suggested that the complexity of the gas exchanging surface might be increased by mechanisms other than alveolar multiplication. ${ }^{44}$ What has become clear is that the postpneumonectomy increase in lung tissue is predominantly localised in the parenchyma. Most existing evidence from animal experiments suggests that the postpneumonectomy growth of the conducting airways is less than that of the alveoli. ${ }^{45}$ In an attempt to analyse the end result of pneumonectomy early in life, a study of adult ferrets showed that the airways had failed to grow to the same extent as the lung parenchyma. ${ }^{46}$ In summary, current findings from animal experiments suggest that a substantial amount of compensatory growth occurs after pneumonectomy, that these mechanisms involve an increase in tissue and some remodelling, and that they are more prominent in the parenchyma.

To what extent do these mechanisms depend on the age at which resection of lung tissue is performed? An age factor is suggested by the distinctly different results found in animals of the same species pneumonectomised at different ages. Alveolar multiplication was found to be prominent in very young rats, lengthening of alveolar walls in somewhat older animals, and predominantly overinflation in mature ones. ${ }^{47}$ Such findings are supported by older studies in cats and dogs which reported alveolar multiplication in immature animals and distension of existing structures in adult ones. ${ }^{48} 49$ However, the existence of alveolar multiplication after resection of lung tissue in very young animals does not in itself prove that this process is compensating for the surgical loss of structure and function, as such alveolar multiplication normally occurs in the postnatal period in several species such as mice, rats, and humans. ${ }^{41}$ In humans this increase in the number of alveoli continues for the first two years of life..$^{50-52}$ Experiments with beagle dogs suggested that postpneumonectomy alveolar multiplication only occurs for a brief period and does not increase the number of alveoli above what is normal for that lung in the mature adult. ${ }^{53}$ This suggests that the lung might be genetically programmed to develop quantitatively and qualitatively only to a certain predefined stage. If this was the case, it would follow that the age at which a con- genital malformation is resected has relatively little relevance to the structural and functional end result in the adult.

While animal studies of postpneumonectomy compensatory lung growth have mainly (but not exclusively) used morphometric techniques, conclusions from studies of human subjects are predominantly based on pulmonary function measurements. Here, evidence for a compensatory response is thought to be present when larger lung volumes than that expected from the amount of tissue resected are found, and increased ratios of residual volume (RV) to total lung capacity (TLC) suggest predominantly distension of the remaining parenchyma. ${ }^{41}$ Such an approach, however, remains unable to define the presence and/or amount of remodelling that might occur in the parenchyma of the remaining lung. Besides this caveat, the issue is complicated by the fact that the existing literature on the functional outcome of lung tissue resection in children remains controversial. Some work reported static lung volumes and a transfer factor that were reduced by approximately the amount predicted from the size of lung tissue removed.$^{54}$ In contrast, several other studies have found evidence for the existence of some compensatory growth which, however, was interpreted as being incomplete..$^{55-57}$ One other study reported a complete volume response after lobectomy for congenital lobar emphysema in infancy. ${ }^{58}$ Interestingly, lung volumes in this study tended to be higher in subjects who underwent resection of larger lobes. This would suggest that a signal of a certain dimension is required to trigger a substantial compensatory volume response.

In conclusion, there is little doubt that some compensatory growth occurs after the resection of lung tissue, and some evidence suggests that this mechanism may be more effective and extensive in infants and young children than in older subjects. However, the extent and the nature of these mechanisms has in many aspects remained unclear. Consequently, the question whether compensatory growth argues for the surgical resection of a lung malformation at the youngest possible age or not cannot be answered conclusively on the basis of presently existing evidence. In analogy, the age at which resection of lung tissue has occurred does not allow definitive conclusions as to the extent to which subsequent growth has compensated in terms of structure and function.

\section{Expectant management}

There is an increasing number of patients in whom a cystic malformation diagnosed in infancy or childhood is managed conservatively. This especially pertains to CLE but other cystic lesions, as long as they remain asymptomatic, may also qualify for expectant treatment. However, CAM might be an exception as this malformation has repeatedly been reported to predispose to the development of bronchoalveolar carcinoma and rhabdomyosarcoma. ${ }^{59}$

There is some concern that the growth of the remaining lung might be inhibited by a non-resected hyperinflated lobe or a space occupying cystic lesion. However, a study in which the lung function of patients after surgical resection of CLE was compared with that of children in whom CLE had been managed expectantly revealed a normal growth rate of functional lung tissue for both groups. ${ }^{60}$ Thus, the functional end result in an adult does not appear to be influenced significantly by the presence or absence of the lesion. It follows that successful expectant paediatric management should be continued into adulthood.

\section{Late presentation}

In rare cases cystic malformations may not be diagnosed until adolescence or adulthood. Such a late clinical presentation will generally be triggered by an infection of the lesion. It follows that recurrent localised pneumonitis and abscess formation in an adult patient should lead to inclusion of these malformations in the diagnostic possibilities. Alternatively, an 
asymptomatic lesion may be discovered coincidentally on a chest radiograph that was taken for another reason. Detection of a cystic malformation does not automatically call for its surgical resection. Rather, the pros and cons of surgery should be considered carefully after a thorough diagnostic evaluation. As a useful rule of the thumb one can expect that a cystic malformation, once infected, will continue to cause symptoms and damage and will therefore require surgical intervention. On the other hand, it is equally sound to reason that a malformation that has remained asymptomatic until being discovered coincidentally in adulthood is not very likely to cause complications in the future and thus might best be managed expectantly. In case of doubt, the adult pulmonologist confronted with such a case should consult with a paediatric respiratory physician who is experienced in managing congenital malformations of the lower respiratory tract. One consideration that is uncommon in paediatrics is that a lesion suspected to be a previously undiagnosed malformation may be better resected when malignancy cannot be ruled out conclusively by other diagnostic means.

\section{CONGENITAL DIAPHRAGMATIC HERNIA (CDH) Paediatric presentation}

$\mathrm{CDH}$ is a severe respiratory malformation that occurs with a prevalence of about 0.3 cases per 1000 births ${ }^{61-63}$ More than 95\% of the congenital defects are located in the posterolateral part of the diaphragm; about $85 \%$ of these "Bochdalek type" defects are found on the left side..$^{62}$ In more than one third of all cases CDH is associated with other congenital anomalies that involve the cardiovascular, genitourinary, central nervous, or skeletal systems. ${ }^{63}{ }^{64} \mathrm{CDH}$ stems from incomplete development of the septum transversum that normally separates the body cavities between the third and ninth weeks of fetal life. ${ }^{63}$ As a result, abdominal viscera are found in the chest and the lungs are hypoplastic. This lung hypoplasia is more severe on the side of the defect; the ipsilateral lung is small, has reduced size bronchi with less branching, a severely decreased alveolar surface, and a pulmonary arterial tree with a reduced number of divisions and an increased thickness of arteriolar walls. ${ }^{6566}$ The degree of lung hypoplasia is the most critical factor for prognosis, with survival becoming increasingly unlikely in cases where the lung volume deficit approaches $50 \% .{ }^{67}$ The presence of a near normal lung volume before repair rules out fatal pulmonary hypoplasia and suggests that survival will depend on the successful management of pulmonary hypertension. ${ }^{68}$

Most cases of $\mathrm{CDH}$ present with severe symptoms in the first 24 hours of life. As the malformation can be diagnosed prenatally by ultrasonography, a child with $\mathrm{CDH}$ should be delivered into a medical setting that is optimally prepared for the emergency management of this malformation. Such management commences in the delivery room and continues with early intensive care, surgical repair, and postoperative intensive care. Throughout the last two decades the complexity and sophistication of $\mathrm{CDH}$ management has increased considerably, with the introduction of high frequency oscillatory ventilation and extracorporeal membrane oxygenation being two important advances. ${ }^{6970}$ Notwithstanding these advances, $\mathrm{CDH}$ remains a major challenge to neonatal intensive care and surgery, as is evident from recent survival rates that still only cluster around $60 \% .{ }^{63} 6970$

\section{Long term outcome}

There have been many studies of the clinical course of $\mathrm{CDH}$ and of the radiological and functional result after successful neonatal repair. Today, however, such published long term outcomes have to be interpreted with caution as they describe the survivors of past medical and surgical management strategies. The management has changed and improved considerably and, as a result, patients with more severe congenital defects and more severe lung hypoplasia will now tend to survive, albeit for the price of more residual damage and morbidity. Therefore, from today's perspective the rather favourable outcome reported in older studies must be seen, at least in part, as a sampling artefact. More long term morbidity should be expected for present and future CDH survivors.

Survivors of CDH seem to suffer more severely from viral respiratory infections in infancy and early childhood but, thereafter, most are able to lead a normal life without significant respiratory morbidity and to participate in regular physical activity including sports. ${ }^{71-76}$ Occasionally, however, there is significantly more long term morbidity with failure to thrive and recurrent bronchitis. ${ }^{77-79} \mathrm{~A}$ few patients only survive with a severe respiratory handicap requiring long term tracheostomy and mechanical ventilation. ${ }^{80}$

Chest radiographs after repair of $\mathrm{CDH}$ range from normal findings to a radiolucent lung field on the side of the former defect. ${ }^{11}{ }^{71-73} 7581$ Pulmonary function tests in CDH survivors tend to show mild to moderate obstructive lung function anomalies. ${ }^{71-7582}$ In addition, some patients present with normal pulmonary function tests and some with a restrictive pattern of changes. ${ }^{7274818384}$ Many CDH survivors show airway hyperresponsiveness when subjected to relevant challenge testing. ${ }^{75} 82$ In contrast to patients with bronchial asthma, however, CDH survivors, while responding positively to pharmacological challenges, do not appear to be hyperresponsive to metabisulphite; this suggests that their bronchial hyperresponsiveness might stem simply from altered airway geometry. ${ }^{82}$ Lung perfusion scans invariably show persisting underperfusion on the side of the former hernia. ${ }^{63717375818384}$ There is hardly any information on the status of the respiratory pump after neonatal repair of $\mathrm{CDH}$; radiologists have observed an abnormal contour and an impaired motion of the repaired hemidiaphragm. ${ }^{11}$

As children with $\mathrm{CDH}$ often require extended preoperative and postoperative intensive care including artificial ventilation, the question arises whether the entire spectrum of the above listed sequelae are explained by residual lung hypoplasia or might stem, at least in part, from damage inflicted by long term mechanical ventilation. This question was addressed by a more recent study that compared the outcome of $\mathrm{CDH}$ patients with that of other children without $\mathrm{CDH}$ who underwent similar neonatal intensive care. ${ }^{82}$ These authors found no difference in the lung function results between the two groups of patients and, in addition, the duration of artificial ventilation tended to correlate negatively with spirometric measurements. They concluded that residual lung function defects in $\mathrm{CDH}$, including airway hyperresponsiveness, are as much or more the result of artificial ventilation as of lung hypoplasia. Normal or near normal lung volumes in CDH survivors suggest that some compensatory lung growth might take place after neonatal repair. ${ }^{72} 74^{75} 82-85$ In addition, the transfer factor was found to be within normal limits in $\mathrm{CDH}$ survivors, suggesting the presence of a normal diffusion surface. ${ }^{82}$ This, however, does not necessarily imply that postoperative compensatory lung growth results in a normalised number of alveoli. A few reports on lung morphology after the neonatal repair of $\mathrm{CDH}$ describe an increase in alveolar size, especially on the ipsilateral side. ${ }^{86} 87$ This suggests that lung distension contributes significantly to the observed normalisation of lung volume and that compensatory alveolar multiplication remains, at best, incomplete. Persisting hypoperfusion of the ipsilateral lung is a finding to be expected as the number of divisions and the size of the pulmonary arterial tree is reduced in the ipsilateral lung in neonates with $\mathrm{CDH}$, and significant postnatal growth cannot be expected for a system in which the formation of new generations does normally not occur after the 16th week of gestation. ${ }^{86} 88$

Residual defects in $\mathrm{CDH}$ are not restricted to the respiratory system. There is a high prevalence of gastro-oesophageal reflux in CDH survivors. ${ }^{77-79818990}$ Speculatively, this is explained by the frequently occurring congenital absence of the 
perioesophageal portion of the diaphragm. ${ }^{77} 79$ Hiatus hernia, susceptibility to intestinal obstruction, and recurrence of diaphragmatic hernia are further components of a long term gastrointestinal morbidity which may be observed after the repair of $\mathrm{CDH}^{63}{ }^{68}{ }^{90}$ The neurodevelopmental outcome in patients with $\mathrm{CDH}$ is comparable to that of other neonates requiring intensive care and extracorporeal membrane oxygenation. ${ }^{6377} 79$ Occasionally there is considerable chronic morbidity from other associated congenital anomalies.

\section{Late presentation}

Most patients with CDH present within the first 24 hours of life. However, there are a few cases with delayed presentation who develop the first symptoms later in childhood or even as adults. ${ }^{91-93}$ The presenting symptoms are usually gastrointestinal and the ipsilateral lung is of normal size or only minimally hypoplastic. ${ }^{63}$ Late presentation of diaphragmatic hernia is a poorly understood entity; some have challenged the concept of these defects being congenital and have suggested that late presenting diaphragmatic hernias are acquired. ${ }^{94}$

\section{OTHER MALFORMATIONS}

There are numerous other rare malformations of the lower respiratory tract that cannot be discussed in detail in this review. Congenital tracheal stenosis and tracheomalacia are observed with vascular rings (double aortic arch, pulmonary artery sling) but also in association with congenital heart disease and camptomelic dysplasia. Congenital bronchial stenosis occurs predominantly in the main stem or middle lobe bronchi. Foregut cysts may not only manifest as bronchogenic cysts but also as intramural oesophageal or posterior mediastinal cysts. Unilateral pulmonary or lobar agenesis may mimic neonatal atelectasis and the Scimitar syndrome might be considered an extreme variant of the sequestration spectrum. The lymphatic and the vascular systems of the lung contribute congenital pulmonary lymphangiectasis and congenital pulmonary arteriovenous fistula to this collection of rare malformations. For details of these conditions the reader is referred to relevant textbook articles. ${ }^{18} 19$

\section{CONCLUSIONS}

Both early surgery and paediatric expectant management result in a patient who ultimately will reach adolescence and adulthood with some residual respiratory impairment or a persisting lesion. Thus, informed adult pulmonologists are needed who can competently take over from their paediatric colleagues. Furthermore, adult physicians may be challenged by a late manifestation or coincidental discovery in adulthood.

Congenital malformations of the lower respiratory tract thus call for well organised cooperation between paediatric and adult pulmonologists to ensure a smooth medical transition from childhood to adulthood. In the case of early surgery, the patient may reach adulthood in good general health but with a somewhat damaged or undersized respiratory tract. Such residual impairment-whether it stems from the original malformation, surgical intervention, or neonatal intensive care-might later interact with environmental factors, aging, or concomitant respiratory disease to cause a reduction or rapid loss of respiratory reserve. At present there are no conclusive data concerning the end result of such interactions in the aging adult and this question will have to be investigated in the future. Patients might benefit from relevant advice and more intensive and frequent medical supervision. At present adult survivors of neonatal surgery and intensive care present a relatively benign clinical picture. This, however, will change progressively towards more residual damage and persisting respiratory morbidity when children who now survive larger and more severe malformations as a result of modern surgical techniques and sophisticated neonatal intensive care reach adulthood.
Patients in whom a malformation has been managed expectantly throughout childhood also need a well organised transition from paediatric into adult care. As late complications may occur (albeit not very likely), the adult pulmonologist requires detailed information about the malformation, diagnostic findings, and all considerations that were of relevance when conservative management was chosen. In general it is reasonable to continue expectant management into adulthood in these patients.

Finally, the adult physician who is confronted with the late manifestation of a congenital malformation will need some knowledge of the subject to plan a targeted diagnostic approach and adequate therapeutic management. In such cases, consultation with an experienced paediatric pulmonologist will provide a helpful second opinion.

In conclusion, congenital malformations of the lower respiratory tract will predominantly remain an arena for paediatric players but the adult pulmonologist might occasionally find him/herself being called from the bench onto the field during an important stage of the game.

\section{Authors' affiliations}

M S Zach, E Eber, Respiratory and Allergic Diseases Division, Paediatric Department, University of Graz, Austria

Correspondence to: Prof $\operatorname{Dr} M$ Zach, Klinische Abteilung für Paed. Pulmonologie/Allergologie, Univ Klinik für Kinder- und Jugendheilkunde, Auenbruggerplatz 30, A-8036 Graz, Austria;

maximilian.zach@kfunigraz.ac.at

Accepted 19 March 2002

\section{REFERENCES}

1 Azoulay D, Regnard JF, Magdeleinat $P$, et al. Congenital respiratory-esophageal fistula in the adult. J Thorac Cardiovasc Surg 1992; 104:381-4.

2 Kluth D, Steding G, Seidl W. The embryology of foregut malformations. J Pediatr Surg 1987;22:389-93.

3 Spitz L. Esophageal atresia and tracheoesophageal fistula in children. Curr Opin Pediatr 1993;5:347-52.

4 Okada A, Usui N, Inone $M$, et al. Esophageal atresia in Osaka: a review of 39 years experience. J Pediatr Surg 1997;32:1570-4.

5 Haight C, Towsley HA. Congenital atresia of the esophagus and tracheoesophageal fistula: extrapleural ligation of fistula and end-to-end anastomosis of esophageal segments. Surg Gynecol Obstet 1943;76:672-80.

6 Wailoo MP, Emery JL. The trachea in children with tracheo-oesophageal fistula. Histopathology 1979;3:329-38.

7 Filler RM, Messineo A, Vinograd I. Severe tracheomalacia associated with esophageal atresia: results of surgical treatment. J Pediatr Surg 1992;27:1136-41.

8 Crispin AR, Friedland GW, Waterston DJW. Aspiration pneumonia and dysphagia after technically successful repair of oesophageal atresia. Thorax 1966;21:104-10

9 Dudley NE, Phelan PD. Respiratory complications in long-term survivors of oesophageal atresia. Arch Dis Child 1976;51:279-82.

10 Milligan $\mathbf{D}$, Levison $\mathrm{H}$. Lung function in children following repair of tracheoesophageal fistula. J Pediatr 1979;95:24-7

11 Griscom NT. Respiratory problems of early life now allowing survival into adulthood: concepts for radiologists. AJR 1992;158:1-8.

12 Benjamin B, Cohen D, Glasson M. Tracheomalacia in association with congenital tracheoesophageal fistula. Surgery 1976;79:504-8.

13 Couriel JM, Hibbert $M$, Olinsky A, et al. Long term pulmonary consequences of oesophageal atresia with tracheo-oesophageal fistula. Acta Paediatr Scand 1982;71:973-8.

14 Biller JA, Allen JL, Schuster SR, et al. Long-term evaluation of oesophageal and pulmonary function in patients with repaired esophageal atresia and tracheoesophageal fistula. Dig Dis Sci 1987;32:985-90.

15 Laks H, Wilkinson R, Schuster S. Long-term results following correction of esophageal atresia with tracheoesophageal fistula: a clinical and cinefluorographic study. J Pediatr Surg 1972;7:591-7.

16 Durning RP, Scoles PV, Fox OD. Scoliosis after thoracotomy in tracheoesophageal fistula patients. J Bone Joint Surg 1980;62:1 156-9

17 Cooke FN, Blades B. Cystic disease of the lungs. J Thorac Surg 1952;28:546-73.

18 Salzberg AM, Krummel TM. Congenital malformations of the lower respiratory tract. In: Chernick V, Kendig EL, eds. Disorders of the respiratory tract in children. Philadelphia: Saunders, 1990: 227-67

19 Clements BS. Congenital malformations of the lungs and airways. In: Taussig LM, Landau LI, eds. Pediatric respiratory medicine. St Louis: Mosby, 1999: 1106-36. 
20 Stocker JT, Madewell JE, Drake RM. Congenital cystic adenomatoid malformation of the lung. Classificiation and morphologic spectrum. Hum Pathol 1977;8:155-64.

21 Madewell JE, Stocker JT, Korsower JM. Cystic adenomatoid malformation of the lung: morphologic analysis. Am J Radiol 1975;124:436-43.

22 Heij HA, Ekkelkamp S, Vos A. Diagnosis of congenital cystic adenomatoid malformation of the lung in newborn infants and children. Thorax 1990;45: 122-5.

23 Wolf SA, Hertzler JH, Philippart AJ. Cystic adenomatoid dyplasia of the lung. J Pediatr Surg 1980;15:925-9.

24 Wesley JR, Heidelberger KP, DiPietro MA, et al. Diagosis and management of congenital cystic disease of the lung in children. J Pediatr Surg 1986;21:202-7.

25 Coran AG, Drongowski R. Congenital cystic disease of the tracheobronchial tree in infants and children. Experience with 44 consecutive cases. Arch Surg 1994; 129:521-7.

26 Browdie D, Todd D, Agnew R, et al. The use of "nonanatomic" pulmonary resection in infants with extensive congenital adenomatoid malformation of the lung. J Thorac Cardiovasc Surg 1993;105:732-6.

27 Khalil KG, Kilman JW. Pulmonary sequestration. J Thorac Cardiovasc Surg 1975;70:928-37.

28 Flye MW, Conley M, Silver D. Spectrum of pulmonary sequestration. Ann Thorac Surg 1976;22:478-82.

29 Collin PP, Desjardins JG, Khan AH. Pulmonary sequestration. J Pediatr Surg 1987;22:750-3.

30 Thilenius OG, Ruschhaupt DG, Replogle RL, et al. Spectrum of pulmonary sequestration: association with anomalous pulmonary venous drainage in infants. Pediatr Cardiol 1983;4:97-103.

31 Carter R. Pulmonary sequestration. Ann Thorac Surg 1969;7:68-88.

32 Durnin RE, Lababidi Z, Butler C, et al. Bronchopulmonary sequestration. Chest 1970;57:454-9

33 Clements BS, Warner JO, Shinebourne EA. Congenital bronchopulmonary vascular malformations: clinical application of a simple anatomical approach in 25 cases. Thorax 1987;42:409-16.

34 Clements BS, Warner JO. The crossover lung segment: congenital malformation associated with a variant of Scimitar syndrome. Thorax 1987;42:417-9

35 Lincoln JCR, Stark J, Subramanian S, et al. Congenital lobar emphysema. Ann Surg 1971;173:55-62.

36 Keith HH. Congenital lobar emphysema. Pediatr Ann 1977;6:34-41.

37 Roguin N, Peleg H, Lemer J, et al. The value of cardiac catherization and cineangiography in infantile lobar emphysema. Pediatr Radiol 1980;10:71-4.

38 Hislop A, Reid L. New pathological findings in emphysema of childhood: 1. Polyalveolar lobe with emphysema. Thorax 1970;25:682-90.

39 Man DWK, Hamdy MH, Hendry GMA, et al. Congenital lobar emphysema: problems in diagnosis and management. Arch Dis Child 1983;58:709-12.

40 Shannon DC, Todres ID, Moylan FMB. Infantile lobar hyperinflation: expectant treatment. Pediatrics 1977;59:1012-8.

41 Cagle PT, Thurlbeck WM. Postpneumonectomy compensatory lung growth. Am Rev Respir Dis 1988;138:1314-26.

42 Addis T. Compensatory hypertrophy of the lung after unilateral pneumonectomy. J Exp Med 1928;47:51-6.

43 Thurlbeck WM. Postnatal growth and development of the lung. Am Rev Respir Dis 1975;111:803-44

44 Burri PH, Pfrunder HB, Berger LC. Reactive changes in pulmonary parenchyma after bilobectomy: a scanning electron microscopic investigation. Exp Lung Res 1982:4:11-28.

45 Burri PH, Sehovic S. The adaptive response of the rat lung after bilobectomy. Am Rev Respir Dis 1979;1 19:769-77.

46 McBride JT. Postpneumonectomy airway growth in the ferret. J Appl Physiol 1985;58:1010-4

47 Holmes C, Thurlbeck WM. Normal lung growth and response after pneumonectomy in rats at various ages. Am Rev Respir Dis 1979;120:1125-36.

48 Bremer JL. The fate of the remaining lung tissue after lobectomy or pneumonectomy. J Thorac Surg 1937;6:336-43.

49 Longacre JJ, Johansmann R. An experimental study of the fate of the remaining lung following total pneumonectomy. J Thorac Surg 1940;10:131-49.

50 Thurlbeck WM. Postnatal human lung growth. Thorax 1982;37:564-71.

51 Zeltner TB, Caduff JH, Gehr P, et al. The postnatal development and growth of the human lung. I. Morphometry. Respir Physiol 1987:67:247-68.

52 Zeltner TB, Burri PH. The postnatal development and growth of the human lung. II. Morphology. Respir Physiol 1987;67:269-82.

53 Davies P, BcBride J, Murray GF, et al. Structural changes in the canine lung and pulmonary arteries after pneumonectomy. J Appl Physiol 1982;53:859-64.

54 Cook CD, Bucci G. Studies of respiratory physiology in children. IV. The late effects of lobectomy on pulmonary function. Pediatrics $1961 ; 27: 234-42$

55 DeMuth GR, Sloan H. Congenital lobar emphysema: long-term effects and sequelae in treated cases. Surgery 1966;59:601-7.

56 Stiles QR, Meyer BW, Lindesmith GG, et al. The effect of pneumonectomy in children. J Thorac Cardiovasc Surg 1969;58:394-400.

57 Frenckner B, Freyschuss U. Pulmonary function after lobectomy for congenital lobar emphysema and congenital cystic adenomatoid malformation. Scand J Thorac Cardiovasc Surg 1982;16:293-8.

58 McBride JT, Wohl MEB, Strieder DJ. Lung growth and airway function after lobectomy in infancy for congenital lobar emphysema. J Clin Invest 1980;66:962-70.
59 Granata C, Gambini C, Balducci T, et al. Bronchoalveolar carcinoma arising in congenital cystic adenomatoid malformation in a child: a case report and review on malignancies originating in congenital cystic adenomatoid malformation. Pediatr Pulmonol 1998;25:62-6.

60 Eigen H, Lemen R, Waring WW. Congenital lobar emphysema: long-term evaluation of surgically and conservatively treated children. Am Rev Respir Dis 1976;113:823-31

61 Wenstrom KD, Weiner CP, Hanson JW. A five-year statewide experience with congenital diaphragmatic hernia. Am J Obstet Gynecol $1991 ; 165: 838-42$

62 Torfs CD, Curry CJR, Bateson TF, et al. A population based study of congenital diaphragmatic hernia. Teratology 1992;46:555-65.

63 Thibeault DW, Sigalet DL. Congenital diaphragmatic hernia from the womb to childhood. Curr Probl Pediatr 1998;28:5-25

64 Langham MR, Kays DW, Ledbetter DJ, et al. Congenital diaphragmatic hernia: epidemiology and outcome. Clin Perinatol 1996;23:671-88.

65 Geggel RL, Murphy JD, Langleben D, et al. Congenital diaphragmatic hernia: arterial structural changes and persistent pulmonary hypertension after surgical repair. J Pediatr 1982;107:457-64.

66 Shochat SJ. Pulmonary vascular pathology in congenital diaphragmatic hernia. Pediatr Surg Int 1987;2:331-4

67 Thibeault DW, Haney BM. A minimum of $50 \%$ of predicted lung weight, DNA or total lung volume is needed for survival in infants with congenital diaphragmatic hernia (CDH). Pediatr Res 1996;39:352A.

68 Antunes MJ, Greenspan JS, Cullen JA, et al. Prognosis with preoperative pulmonary function and lung volume assessment in infants with congenital diaphragmatic hernia. Pediatrics 1995;96:1117-22.

69 Azarow K, Messineo A, Pearl R, et al. Congenital diaphragmatic hernia - a tale of two cities: the Toronto experience. J Pediatr Surg 1997;32:395-400.

70 Wilson JM, Lund DP, Lillehei CW, et al. Congenital diaphragmatic hernia-a tale of two cities: the Boston experience. J Pediatr Surg 1997:32:401-5.

71 Reid JS, Hutcherson RJ. Long-term follow-up of patients with congenital diaphragmatic hernia. J Pediatr Surg 1976;11:939-42.

72 Kerr AA. Lung function in children after repair of congenital diaphragmatic hernia. Arch Dis Child 1977;52:902-3.

73 Falconer AR, Brown RA, Helms $\mathrm{P}$, et al. Pulmonary sequelae in survivors of congenital diaphragmatic hernia. Thorax 1990;45:126-9.

74 Wischermann A, Holschneider AM, Hübner U. Long-term follow-up of children with diaphragmatic hernia. Eur J Pediatr Surg 1995;5:13-8.

75 Vanamo K, Rintala R, Sovijärvi A, et al. Long-term pulmonary sequelae in survivors of congenital diaphragmatic defects. J Pediatr Surg 1996;31:1096-100

76 Zaccara A, Turchetta A, Calzolari A, et al. Maximal oxygen consumption and stress performance in children operated on for congenital diaphragmatic hernia. J Pediatr Surg 1996;31:1092-5.

77 VanMeurs KP, Robbins ST, Reed VL, et al. Congenital diaphragmatic hernia: Long-term outcome in neonates treated with extracorporeal membrane oxygenation. J Pediatr 1993;122:893-9.

78 Naik S, Greenough A, Zhang Y, et al. Prediction of morbidity during infancy after repair of congenital diaphragmatic hernia. J Pediatr Surg 1996;31:1651-4.

79 Nobuhara KK, Lund DP, Mitchell J, et al. Long-term outlook for survivors of congenital diaphragmatic hernia. Clin Perinatol 1996;23:873-87.

80 Greenholz SK. Congenital diaphragmatic hernia: an overview. Semin Pediatr Surg 1996:5:216-23.

81 Delepoulle F, Martinot A, Leclerc F, et al. Devenir a long terme des hernies diaphragmatiques congenitales. Etude de 17 patients. Arch $\mathrm{Fr}$ Pediatr 1991;48:703-7.

82 lisselstijn $\mathbf{H}$, Tibboel D, Hop WJC, et al. Long-term pulmonary sequelae in children with congenital diaphragmatic hernia. Am J Respir Crit Care Med 1997; 155: 174-80.

83 Wohl ME, Griscom T, Strieder DJ, et al. The lung following repair of congenital diaphragmatic hernia. J Pediatr 1977;90:405-14.

84 Wohl MEB. Pulmonary sequelae of insults to the lung in early life. Pediatr Pulmonol 1995;19:90-5.

85 Landau LI, Phelan PD, Gillam GL, et al. Respiratory function after repair of congenital diaphragmatic hernia. Arch Dis Child 1977;52:282-6.

86 Hislop AA, Reid L. Persistent hypoplasia of the lung after repair of congenital diaphragmatic hernia. Thorax 1976;31:450-5.

87 Thurlbeck WM, Kida K, Langston C, et al. Postnatal lung growth after repair of diaphragmatic hernia. Thorax 1979;34:338-43.

88 Reid L. The lung: its growth and remodeling in health and disease. AJR 1977;129:777-88

89 Nagaya M, Akatsuka H, Kato J. Gastrooesophageal reflux occuring after repair of congenital diaphragmatic hernia. J Pediatr Surg 1994;29: 1447-51.

90 Vanamo K, Rintala RJ, Lindahl H, et al. Long-term gastrointestinal morbidity in patients with congenital diaphragmatic defects. J Pediatr Surg 1996;31:551-4.

91 Kirkland JA. Congenital posterolateral diaphragmatic hernia in the adult. Br J Surg 1959:47:16-22.

92 Osebold WR, Soper RT. Congenital posterolateral hernia past infancy. Am J Surg 1976;131:748-54.

93 Nitecki S, Bar-Maor JA. Late presentation of Bochdalek hernia: our experience and review of the literature. Isr J Med Sci 1992;28:711-4.

94 Wiseman NE, McPherson RI. "Acquired" congenital diaphragmatic hernia. J Pediatr Surg 1977;12:657-65. 